Association for Information Systems

AIS Electronic Library (AISeL)

Conceptualizing Role Development in Agile Transformations:

Deriving Design Goals and Principles for Agile Roles

Rebecca Lueg

Leuphana Universität Lüneburg

Paul Drews

Leuphana Universität Lüneburg

Follow this and additional works at: https://aisel.aisnet.org/wi2021

Lueg, Rebecca and Drews, Paul, "Conceptualizing Role Development in Agile Transformations: Deriving Design Goals and Principles for Agile Roles" (2021). Wirtschaftsinformatik 2021 Proceedings. 16. https://aisel.aisnet.org/wi2021/XStudent/Track03/16

This material is brought to you by the Wirtschaftsinformatik at AIS Electronic Library (AISeL). It has been accepted for inclusion in Wirtschaftsinformatik 2021 Proceedings by an authorized administrator of AIS Electronic Library (AISeL). For more information, please contact elibrary@aisnet.org. 


\title{
Conceptualizing Role Development in Agile Transformations: Deriving Design Goals and Principles for Agile Roles
}

\author{
Rebecca Lueg ${ }^{1}$, Paul Drews ${ }^{1}$ \\ ${ }^{1}$ Leuphana University Lüneburg, Institute of Information Systems, Lüneburg, Germany \\ r.lueg@web.de,paul.drews@leuphana.de
}

\begin{abstract}
Design knowledge on agile role development is still nascent. Following the call for a theoretical and empirical investigation into the formation of roles in agile transformations, we elicited three design goals, six design principles and defined the pathway to achieving these goals. Our concept provides new insights into the dynamic and cohesive character of agile roles and adds role development as a key activity to the core of agile transformation. The results are based on a qualitative research methodology and design science research. We contribute to theory by providing a grounded approach for the situational development of dynamic agile roles based on design goals and principles, while practice can profit from the approach as our concept provides greater flexibility than the strict role definitions of agile frameworks.
\end{abstract}

Keywords: Agile Roles, Agile Transformation, Design Goals and Principles

\section{$1 \quad$ Introduction}

With the emergence of agile software development methods since the late 1990s [1-4], especially software dominated companies have an increasing interest in applying agile methodologies and agile frameworks. Scaling agile methods beyond the team level and conducting an agile transformation of entire departments or organization wide became a protruding and contemporary phenomenon [5-7]. Scaled agile frameworks like SAFe [8], Less [9], or DAD [10] provide guidance for conducting an agile transformation and maintaining an agile way of working, including suggestions and rules on how to apply certain agile methods, define artifacts, and describe roles and role structures. The understanding of agility as the ability to create change rapidly, embrace change reactively and proactively, and learn from change [11] is mostly applied to agile methods and processes. The development and evaluation of roles in agile settings remains a black-box. We argue that agility also impacts the design of roles and calls for a concept that supports the contextualized development of roles.

Although nascent research and theoretical fundamentals exist, the development of roles in agile transformation processes is mostly neglected [12], [13]. Previous research outlines the precise role definitions in practical frameworks like SAFe [8] and Scrum [14]. However, the role transition in transformation processes are still unclear [15]. For

16th International Conference on Wirtschaftsinformatik,

March 2021, Essen, Germany 
instance, Moe et al. [13] postulate a lack of research regarding the process of forming teams and defining roles in agile settings. Initial research, however, provides implications of role development in agile and software development settings, giving insights into influencing factors like the system perspective [9, 16], and the product or artifact-orientation [17]. Jovanović et al. [12], emphasize the difficulties of role transitioning in agile transformations, specifically the different character of agile roles and the challenges of agile role development and transition. Besides the Information Systems perspective, organization theory and sociological concepts provide also approaches to the structuring of work (e.g. [18], [19]), and a starting point for the terminology of roles and their dynamic evolvement [20]. However, these concepts are predominantly suited for stable and predictable environments and traditional coordination practices. Finally, scaled agile frameworks, like SAFe [8], LeSS [9], and $\mathrm{DAD}$ [10], address the need for renewed roles and the formulation of roles as flexible blueprints, as a one-fits-all solution, but neglect the provision of guidance for role development and customization.

As no studies or frameworks explicitly guide the development of roles in agile transformations in conjunction with the underlying principles, we propose to link agile values to the development of the respective roles and thus lay the foundation for a critical reflection of roles and possible strategies for role development and refinement. Therefore, this study is guided by the following two research questions: (RQ1) Which design goals and principles should be considered for developing roles in agile transformations? and (RQ2) How can a concept to develop agile roles look like?

As a contribution, we identify design goals and principles for role development in agile transformations, along with a design concept and a theoretical instantiation. This research follows the design-oriented approach [21] and manifest on the empirical data collection and interpretative qualitative data analysis with the theoretical investigations of literature reviews, concepts, approaches, frameworks, and case studies.

Our presentation of research is structured as follows: First, we provide the theoretical background and the state-of-the-art research on agile transformations and agile roles, along with the investigation of sociological and organizational concepts. Afterwards, we introduce the chosen research methodology, followed by the presentation of the results. Subsequently, we conclude with theoretical and practical implications and an outlook on further research.

\section{Theoretical Background}

In order to continuously and proactively create change, and institutionalize the ability for learning and continuous improvement [11], organizations are scaling up their use of agile methodologies. Agile transformations change processes, collaboration procedures, roles, and mindset beyond the team level [5-7]. Research on agile transformation is gaining increasing momentum highlighting the challenging character of the adoption of agile methods and the thrive for more agility as the organization grows, and the dependencies and complexity between projects and teams increase [22]. 
The research area of roles in agile transformations is diversified and fragmented. Studies in the area of IS focus, for instance, on the importance of having defined roles and their effect on involvement, commitment, and personal responsibility, as well as on the need for ongoing refinement of role definitions [23]. Other studies outline the precise and diverse role definitions in practical frameworks like SAFe and Scrum [15] or focus on specific roles like the architect [24]. Although defining the nature of roles as self-organizing and enabling has become a hallmark of agile methods, less attention is paid to the development of agile roles. A first attempt to identify and develop adequate job descriptions and roles in modern software development teams was proposed by Downey [17] with the artifact-centric skill framework. The study depicts the software development process as mostly comparable between different companies and suitable for creating more adequate role descriptions based on the associated artifacts within a development process.

The theoretical investigation of the role concept in agile transformations extends the research towards interdisciplinary research grounds. The sociological role theory [20] investigates the organization of social behavior and define roles as a group of behaviors and attitudes that are considered to belong together. Role theory assumes that instead of mechanically playing the role, individuals shape and define the roles on their own, in order to interact in a meaningful way with other relevant roles [25]. The development of roles is ascribed to differentiation practices to sort and separate actions. In organizations, roles often face a discrepancy between role definition and role behavior.

In contrast, organization theory addresses roles from the starting point of building organizational structures. As the terminology of positions [18] or jobs [19] is more common, jobs represent the essential building block in organizations and are composed of stable bundles of tasks executed by individuals under administrative titles [26]. The development of organizational structures is part of the intertwined approach of organizational differentiation and integration [27]. Organizational differentiation addresses the question of the most favorable division and allocation of tasks [18], whereas organizational integration focuses on the coordination of tasks. Organization and management theory are criticized for being prescriptive and postulating to place well-understood tasks into stable jobs and therefore being mechanistic and narrow [26], [27]. More recent studies propose the concept of job assembling instead of job design, following the activities of organizing work that impact the allocation of tasks [26]. As today's work differs from the traditional model and is confronted with increasing dynamic environments, like ambiguous, team-oriented, abstract, and changeable work activities [28], studies emphasize the increasing need for taking a system perspective in order to structure tasks [16], [27], along with cross-functionalism and abstract role design [28]. Furthermore, job crafting [29], as physical and cognitive changes made by job holders, and the emergence of teams and group-based forms of working have gained increasing interest by scholars [30], [31].

The literature review of different research disciplines along with the multitude of roles named in scaled agile frameworks, and case studies (e.g. [32-34]), indicate the inadequacy of a one-fits-all approach for agile roles in software development settings. Studies show that role definitions used in the industry vary significantly from those role definitions defined in the frameworks and literature [15]. Role tailoring and role 
customization processes are needed to find the appropriate roles for the relevant project activities and goals. Additionally, the variety of required roles differs with the size of the organization and results in the merging of roles in smaller organizations or the implementation of additional roles in larger ones [15]. Organizational conditions in terms of problem areas and capabilities determine the resulting role definitions and structures, leading from well-defined and detailed role descriptions to abstract understandings of role responsibilities.

As studies named team set-up and role formation as one essential prerequisite for the success of agile transition and adoption [7], [35], a concept for agile role development and a clear definition of the role terminology is needed to support the individual adoption of frameworks and expand the possibilities of role assessment. Furthermore, we follow the research calls for strategies for organizational role structuring [12], [15], the exploration of the development of agile teams [13], and more practical guidance in agile transformations [36], [37], [38].

\section{$3 \quad$ Research Method}

To investigate and develop a concept suitable for identifying agile roles in agile transformations, the research process follows the implications of design science research (DSR) [39], [40]. The DSR methodology postulates a problem-solving paradigm and seeks to create new and innovative artifacts intended to solve an identified organizational problem. This study aims to design an abstract artifact without physical existence, but communication in the form of a concept [41]. The iterative design and development of artifacts facilitate continuous reflection and refinement of the incremental results [21] (see Figure 1).

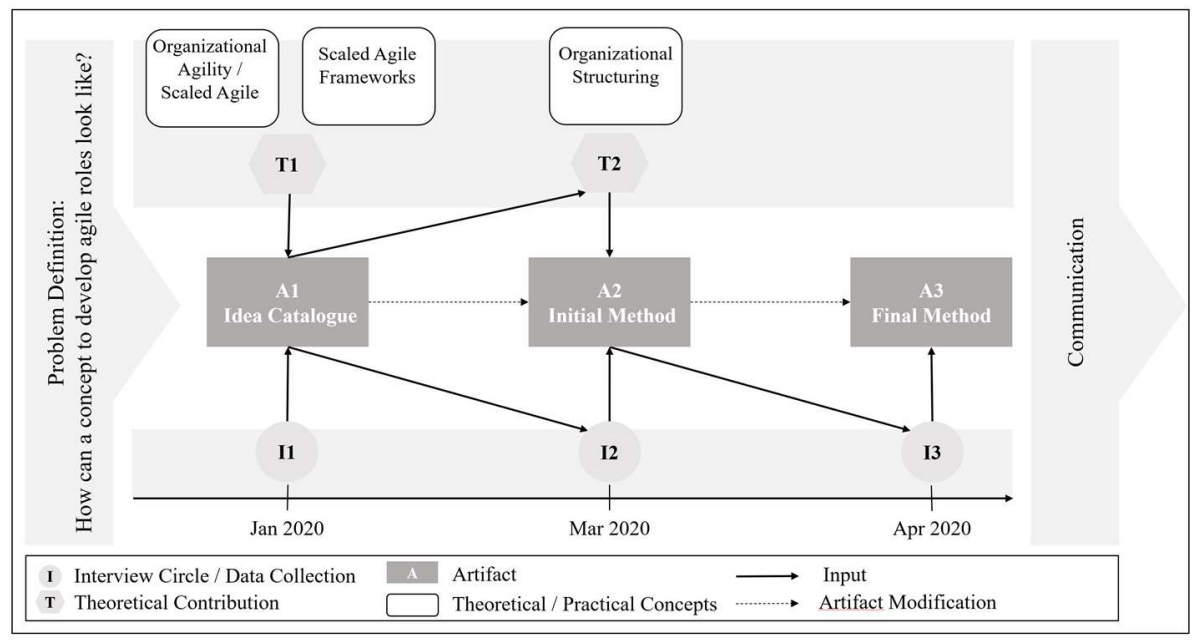

Figure 1. Data Collection and Data Analysis Process 
We base our research on primary and secondary data from multi-case organizational settings. Explorative in-depth interviews were conducted with eleven international experts in the field of agile transformation and scaled agile. The iterative conduction of the interviews led to the division of three interview cycles. The interviews were conducted in December 2019, January 2020, and March / April 2020. After each circle, the data was analyzed and processed. The last interview circle served as a feedback loop, where the designed concept was presented in its entirety. Finally, the company SoftwareCorp was accompanied in the exemplary theoretical application of the artifact, which enriches the collection of data for the final reflection and the rigor of the results. The primary data was collected with international experts from Germany, Netherlands, India, the United States of America, Ireland, Belgium, and Switzerland.

We collected secondary data to enable triangulation of the results, where possible. The secondary data is based on case studies and experience reports on agile transformation and scaling agile. The material was identified in the systematic process of in-depth literature research in academic databases AIS electronic library, EBSCOHost, IEEE explore, and Google Scholar. For the conducted searches, the following search terms were used: scaled, scaling agile, large-scale agile, large-scale scrum, scaling scrum, and agile transformation. The selected articles were analyzed for their richness of information to specific roles, role definitions, and role structures. The objectivity criteria excluded all cases which were not independent from the publisher of a specific scaling agile framework. Ultimately, six cases [33], [34], [42], [43], [44], [32] were identified, which provided enough information to investigate and analyze role definitions and structures. Additionally, sources in the form of three scaled agile frameworks, SAFe [8], LeSS [9], and DAD [10] were also included for best practices in agile roles and role structures.

The data analysis followed the inductive grounded theory approach [45]. The generated data was transcribed and along with the case studies transmitted into the analysis tool MAXQDA. In alignment with the grounded theory approach, the three coding stages, open coding, axial coding, and selective coding were applied (see Appendix for detailed information). Following, design goals and principles were derived from the coding and backed up with theoretical evidence. For the concept building, the core codes were put into relation which derived in a four-phased concept to develop roles in agile transformations. Finally, a summative evaluation approach, with a five-point Likert-scale questionnaire, was applied to receive comprehensive feedback. Furthermore, the evaluations validate the initial results, evaluate the utility, and the level of completeness and applicability [21]. The instantiation at our participating organization, SoftwareCorp, serves as a "proof-of-concept" for the value of the artifact [41] and assessed the originality and benefit.

\section{$4 \quad$ Results}

In the following, we present the (1) design goals (DG), as a requirement for the definition of agile roles and the design principles (DP), as the underlying logic of sufficient agile roles. The resulting (2) concept as a designed artifact is derived from 
the design goals and principles. Finally, (3) an exemplary theoretical instantiation of the artifact for the development of agile role definitions and structures is presented to establish its utility.

\subsection{Design Goals and Principles for Agile Roles}

Design Goals as Requirement for Agile Roles. Design goals (causa finalis) serve as meta-requirements to specify the type of artifact to which the theory applies and reflect the boarders of applicability [46]. We identified three generalizable design goals.

Agility requires organizations to have a customer-centric capacity for fast value creation [47], [35]. Generating customer value corresponds with a strong product focus [48], leading to a rethinking of structures and processes, as well as new ways of working [8]. Agile role definitions and structures demand a corresponding role designing logic, from creating output in different independent silos and strictly task-oriented role definitions towards outcome focus in terms of activities that generate customer value [17]. Hence, the first design goal requires a customer value-based role development process (DG1).

Since the environment and the customer's needs can change continuously, agile roles should incorporate the ability to adapt to change. Allowing freedom of movement in role definitions and structure serves to facilitate the responsiveness of the organization and its ability to adapt [28]. Therefore, the second design goal calls for flexible and adaptable role definitions and structures (DG2). Flexible and adaptable roles are therefore a prerequisite for agility, as, for instance, one expert noted that "a specific job description is [...] not good for an agile transformation, so it doesn't help it is contradicting, even." (TPDT07).

Finally, relentless improvement of role definitions and structures (DG3) serves as the underlying premise, as agility unfolds its potential in turbulent ever-changing environments [49], [50]. SAFe named relentless improvement as one of the critical pillars to unlock agility [8]; also, LeSS suggests continuous improvement by experimenting and providing the organization capability for teams to improve and adapt [9]. Incorporating the premise of relentless improvement emphasizes the dynamic character of agile roles and postulates a non-mechanical approach to ensure sustainable evolvement of agile roles in disruptive environments [37]. One expert (TPAM08) emphasized the importance of relentless improvement, as inevitable impediments necessarily lead to deviation from the role definitions.

Design Principles as Abstract Blueprints for Agile Roles. Design Principles (causa formalis) describe the principles of form and function [46] for developing roles in agile transformations. We identified six principles that serve as an abstract blueprint of the requirements for achieving adequate agile roles.

In order to foster customer value creation (DG1), DP1 implies value stream-driven role definitions and structures. Value streams represent the series of steps needed to create customer value and follow a chronological flow of activities [8], [48]. The underlying goal is to break down barriers between silos and departments to increase efficiency and minimize delays through dependencies and waste [48]. Also, in terms of role development, value streams facilitate the identification of specific roles, teams, and 
actions needed to process the value stream and deliver solutions, by fostering customercentricity, and delivering value in the shortest lead time (DG3).

Agile settings face an increasing need for balancing the relentless focus on delivering customer value (DG1) with technical excellence. As noted by one expert, there is: "the natural friction process between the developer who wants to build [the product] technically perfect, but never finishes, and the Product Owner, who wants to build the perfect product and has this delivery pressure." (TPTL06, translated) that needs to be managed. Responsibility differentiated role definitions and structures as DP2 manage the frictions within a team by splitting the areas of focus. The division of responsibility suggests no form of hierarchy [9]. Instead, it facilitates the most efficient localization and processing of knowledge and activities to achieve a common goal. Concerning the definition of agile roles, DP2 facilitates the design of dynamic role descriptions, as the differentiation of responsibility defines the scope of action for each area within one team.

DP3 targets autonomous decision-making through aligned cross-functional teams in agile role structures. "Team autonomy is a fundamental design principle, $[\ldots]$ because we believe that it is beneficial to working in a faster and more efficient manner, when decisions are being made as far down the line as possible, so, directly in the teams." (TPTL06, translated). Autonomous and flexible teams enable fast value creation (DG1,2) and minimize delay and waste, as a viable decision can be made independently [51]. Diverse and inclusive teams increase the likelihood of being able to act autonomously [13]. An implicit implementation of the premise of autonomy and cross-functionalism in role definitions and structures, support the embedding of an agile mindset into the foundations of the organizational structures of roles.

For relentless improvement (DG3) of the role definitions and structure with continuously changing conditions, DP4 proposes role definition and structure review cycles as necessary routines in the development of agile roles. The routine in the form of regular reviews represents a valuable source of flexibility and change [52] (DG2). One expert proposed three factors in order to review the role structure: "Are we solving the problem we want so solve, is somebody behaving in the expected behavior and [...] what is the perspective of the person himself." (TPDT07). Continuous reflection encourages learning and improvement [8] and does not only promote a central review process of roles, but also recommend role inhabitants to review and redefine themselves as a form of 'role' crafting [29] and how they perceive other roles.

The execution of role review cycles is facilitated by DP5, which proposes focusing on simplicity in role definitions and structures. Simplicity, "the art of maximizing the amount of work not done" [4], postulates the prevention of unnecessary complexity. The application of this DP to agile roles prevent the paths to structural inertia (DG2,3). The implementation of simplicity is manifold. Simplicity can occur in terms of lightweight processes, in forms of knowledge acquisition, or manifest in personal communication between the team and the customer [53].

DP6 advises the development of role definitions and structures to extend towards (product) abstraction level integration. Organizations need to handle a lot of information and knowledge about the product in terms of requirements, on varying levels of abstraction and detail [54]. Agile roles need to tackle these abstraction levels 
from high-level conception to detailed operationalization and the subsequent responsibilities. Therefore, role definitions can be abstracted as the product requirements are assigned; for instance, to the product level, feature level, function level, and component level [54]. It simultaneously promotes a flexible approach, as the levels can change with the customer's requirements (DG2).

As a result of the defined design goals and principles, we define agile roles as a set of responsibilities and expectations of a person or group of people in a social system. Agile roles possess the ability to create themselves, to optimize themselves, and to adapt dynamically and autonomously to constantly changing influences. Agile roles are characterized by an embedded agile mindset as well as by the goal of relentless improvement and self-reflection for the most efficient creation of value.

\subsection{A Concept for Developing Agile Roles in Agile Transformations}

The following concept represents the systematic application of the aforementioned design goals and principles. The concept, as an abstract artifact, shows how organizations can follow the systematic procedure of identifying and designing agile roles. The concept consists of four repetitive phases, which guide organizations through the individual development of roles in the agile transformation (see Figure 2).

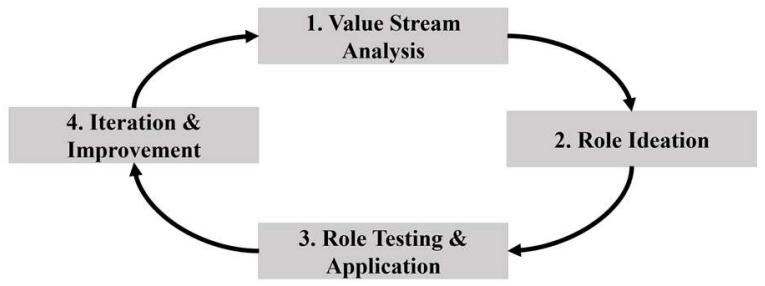

Figure 2. A concept for developing agile roles

1. Value Stream Analysis. The identification of product value streams serves as the starting point for role development and depict the design room for role creation (DP1). Product value streams represent the activity flow and the core processes from a customer perspective, which are necessary for the creation of customer value. Identifying product value streams represents an essential step in rethinking and redefining the role structures, as this demands the construction of cross-functional and silo independent value flows. A high-level description of the activities reduces complexity (DP5) and fosters flexibility (DG2).

2. Role Ideation. Role ideation manifests in the orchestration of the activities to dimensions of responsibility (DP2), derived from a value and product-oriented perspective. The concept distinguished between the (1) product, (2) technology, and (3) flow responsibility dimension. Each dimension consists of a factual and integration area, which, in combination, represent the building blocks for agile roles in each responsibility dimension. The factual areas cover the main areas of content responsibility in the dimensions and serve as a minimum standard, whereas integration 
areas represent necessary integrative aspects. These are essential to align and coordinate all responsibility dimensions.

The Product Responsibility Dimension. The responsibility of the product dimension lies in the ability to represent the customer and adequately serve as their proxy. The factual coverage of the product dimension contains at least: product vision and roadmap, product requirements definition, product requirements prioritization, and product demonstration.

The Technology Responsibility Dimension. The technology dimension takes over the responsibility for delivering working and tested product steps that fit customer needs and generate customer value. The coverage of the technology dimension consists at least of: technical vision and roadmap, technical requirements definition, technical requirements prioritization, and technical development and operations.

The Flow Responsibility Dimension. The flow responsibility dimension acts as an enabler for the other dimensions, fostering an efficient way of working towards fast delivery and a customer value-based role development process. The flow responsibility dimension covers: agile coaching, process management, risk management, release or delivery management, and resource management.

The ideation of roles leads to generic role definitions. Figure 3 gives an example of three product-related roles. The gray marked bars above each factual area indicate the extent to which, for instance, Role III covers the factual area 'Product Requirements definition'. As some requirement definitions are predefined on the overall product level and apply to more than one activity, Role I on the product level covers the remaining responsibilities in this factual area on the higher abstraction level. The dashed areas show that the granularity of the responsibilities regarding requirement definitions vary depending on which team Role III is cooperating with.

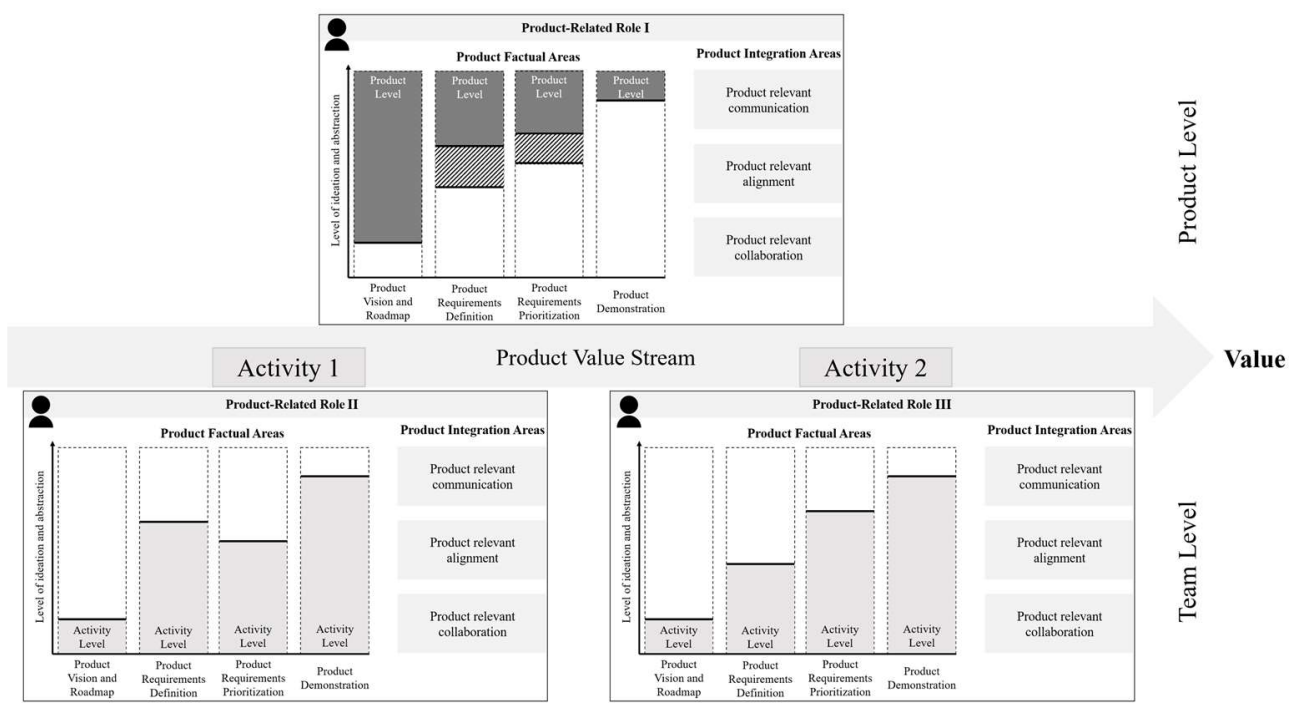

Figure 3. Example of designed product-related roles 
The design for technology- and flow-related roles follows the same systematic. The simplicity of these role definitions (DP5) balances structure with flexibility, as these definitions offer mandatory orientation and guidance while having room for adaptability (DG2). Furthermore, the orientation of agile roles towards different responsibilities and factual areas circumvents the definition of specifying and detailing tasks. The uniform role design approach alleviated the comparability of roles on different levels. It also enables the systematic and logic-guided assessment of possible consequences of role adjustments and changes.

3. Role Testing and Application. The concept suggests validating the resilience and feasibility of the agile roles with a systematic testing phase (DP4). The ideation of the agile roles is tested against three possible challenges. First, people-related challenges, like change resistance or lack of acceptance as, for instance, "most people are used to more traditional job descriptions." (TPPM02). Second, operational challenges, like existing HR instruments, as one expert notes that: "All the instruments don't fit there." (TPPL09, translated), or staffing. Finally, managerial or organizational challenges, like impact and scope of the transformation, or the re-orchestration of decision-making, as noted by one expert: "making decisions is something you have to adjust to." (TPAM08, translated). Testing is a prerequisite for continuous improvement and constant adaptation to changing conditions and emphasizes the utopia of one-fits-all solutions, as these are strongly dependent on organizational resources and capabilities.

4. Iteration and Improvement. Finally, the iteration and improvement phase emphasize the ongoing development cycle and activation of the organizational capacity to develop and adapt roles (DG2,3) (DP4). The generalized nature of the design goals and principles allows the application of various role scenarios and coping mechanisms for occurring challenges. The importance of generalizable principles is emphasized by one expert, who emphasized: "Don't change the principles, [...] only change the structure and the way of working, slightly." (TPDT07). In conclusion, the design of the responsibility dimensions provides a tool to make adaptations and modifications of role definitions and structures which are visible for the role inhabitants. It also facilitates the measurement and reviewal of improvement efforts.

\subsection{Exemplary Instantiation}

The theoretical application represents an instantiation of the artifact. SoftwareCorp is a software development consultancy, supporting the client in the development of a software developer platform and agile transformation. The product encompassed seven teams and over 70 team members. The instantiation shows how SoftwareCorp followed the methodological implications of the developed artifact, as well as what the theoretical result looked like (see Figure 4).

1. Value Stream Analysis. SoftwareCorp focuses on its work on customercentricity and the development of value for the user (DG1). The user journey designed from SoftwareCorp corresponds with the identification of the product value stream, proposed by the aforementioned method (DP1).

2. Role Ideation. SoftwareCorp introduced the product and team level for the initial creation of roles, to avoid complexity added by hierarchy (DP5). The abstraction levels 
(DP6) are differentiated into: user story, feature, and goal. This categorization results from the structure of the road map, breaking down goals into realizable features and feasible user stories. SoftwareCorp applied the suggested factual areas and linked the coverage to the abstraction levels. The factual areas cover in their abstractness the real scenario with its activities at SoftwareCorp. The role ideation phase leads to six generic role definitions for SoftwareCorp. Three on the product level and three on the team level, being applicable for multiple teams.

3. Role Testing and Application. SoftwareCorp evaluates and tests the developed role ideation against the real constellation in practice and the challenge areas mentioned by the method above (DG3). For instance, SoftwareCorp outlines that some people are not accustomed to the agile mindset and the way of working and therefore need more guidance in the form of more detailed role definitions. Additionally, also staffing represents a valid challenge as it is hugely influenced by the available budget and the most suitable staffing constellation. Finally, also resource utilization influences the designed role structure. The chosen constellation is the result of adequately covering the factual areas based on the skills, capabilities, and experiences of the corresponding resources. The implementation of these constellations leads to the open time capacities of certain roles and the coverage of more than one responsibility dimension by one role.

4. Iteration and Improvement. SoftwareCorp outlines that based on experiences, a dynamic role construct is more than necessary as, in reality, roles adapt continuously due to changes in required skills, expertise, or product context. Conscious role reviews increase the observations of role efficacy and adequacy (DP4), whilst still maintaining the focus on learning and improvement above control (DG3). Continuous role review demands generic role definitions that rest on responsibilities and goals instead of tasks.

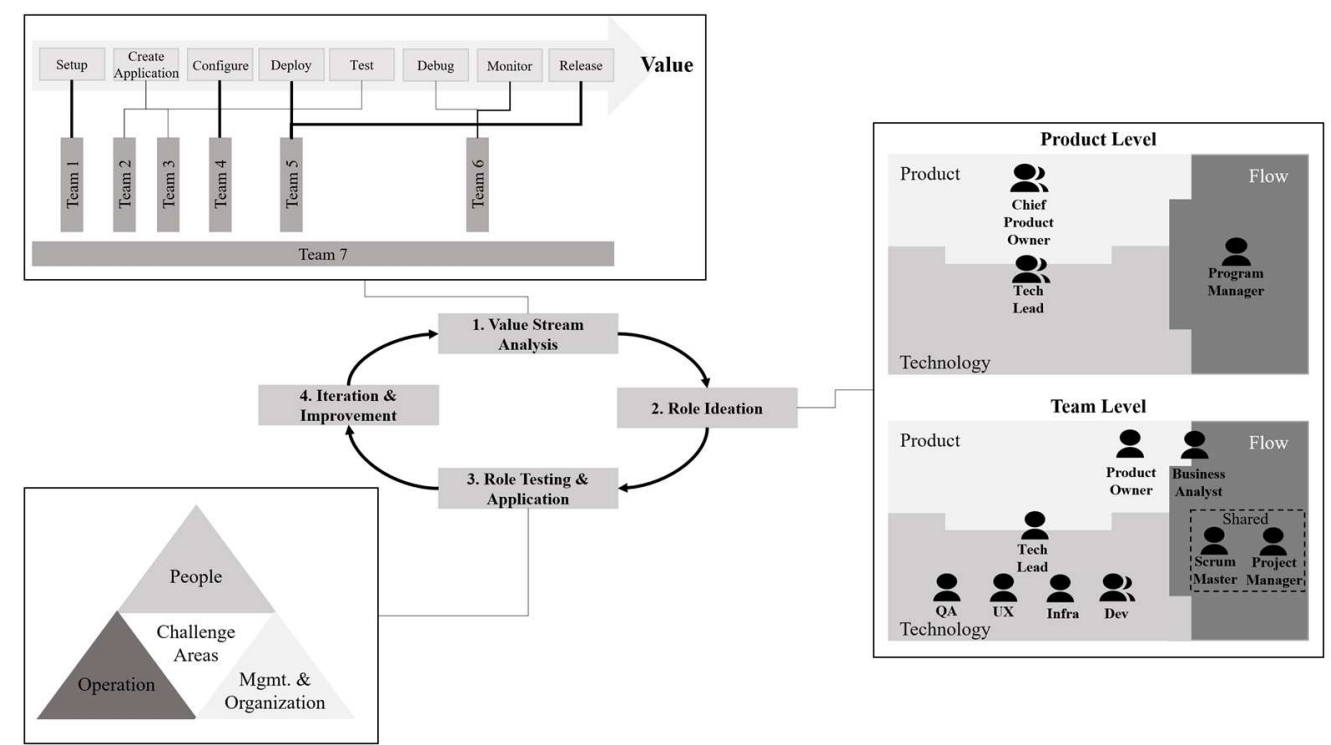

Figure 4. Agile Role Development at SoftwareCorp 


\section{Discussion}

Theoretical Implications. Our research provides several theoretical implications. First, the study extends the theoretical investigation of roles in agile transformations and follows the call for a theoretical analysis of agile role development [24], [15], [12]. This study goes beyond the current research by looking behind the fixed roles offered by frameworks and linking the agile values and principles to the agile role development process. The concept reflects the system perspective [9], [10], by incorporating the identification of value streams, customer-centricity, and changing external and internal influences in the development system of agile roles. Furthermore, this study addresses the proactive side of agile roles and the pursuit of relentless improvement, instead of designing roles in a traditionally reactive nature [18]. The proposition of generic agile role definitions serves as an individual blueprint for roles in an organization but are subject to the principles of relentless improvement and flexibility.

Second, the study addresses the inconsistency of the term 'role' and suggests a convergence of research disciplines to provide a holistic picture of the role phenomena. In theory, different research streams use either the term role [20] or the term jobs [18], whereas some scaled agile frameworks clearly distinguish between the two [9], [10]. Both terms have their advantages in either describing the tasks and the resulting organizational structure or the interactions between individuals that lead to structure and organization. Our data analysis suggests that the design of agile roles could not solely be explained by organizational approaches of traditional differentiation and integration [18], as these approaches are dominantly task-oriented. Moreover, classic integration mechanisms require some form of chain-of-command or treat the chain of command as the mechanism for integration [27]. Newer approaches, such as job design [26] or job crafting [51], also focus on the allocation of tasks, either as a process conducted by managers or other internal authorities, or as the power of job inhabitants to redefine the jobs themselves. The design of agile roles demands a broader orientation anchor than tasks. The derived method phases for role definitions and structures in agile transformations incorporates the idea of job design/assembling [26] as an interrelated process between problem-areas and institutional demands. As a consequence of interaction dynamics, our concept also incorporates the advantages of job crafting through self-reflection and refinement. Therefore, our study follows the idea of defining roles with responsibilities and expectations, rather than tasks and acknowledges the dynamics of interaction as a role structuring premise [20].

Third, the study contributes to the scientific research base in the form of design goals and principles and reflect abstract theoretically and empirically-validated guidelines for the development of agile role definitions and structures. As noted by Gregor and Jones [46], meta requirements aim to develop a design theory suitable for a class of artifacts, typified by these requirements. Therefore, the boundaries of applicability are defined. The design goals apply to the design of agile role definitions and structures and not to a single role structure in one specific organization. This component allows the comparison of new theories with similar goals and scopes [46]. Therefore, the study postulates that agile role definitions and requirements can be abstracted to design goals and principles and sheds light on the object of a role as a dynamic, flexible construct 
which enables value creation in an agile manner. Following this, the derived concept suggests a novel design of agile role development by applying the design goals and principles and thus postulating a modified approach for the structuring of work.

Practical Implications. Our study positions agile role definitions and structures within the context of agile transformations and reflects the matter-of-course implementation of predefined roles from frameworks. Surprisingly, research and practitioners still tend to focus on the optimization of processes and the implementation of new agile practices with the one-fits-all role structure. The investigation of transformation challenges and empirical case studies, however, suggest that many problems have their roots in people-related issues; including, unclear or overlapping roles (e.g. [55], [34]). We recommend practitioners treating agile roles as mutable and thus provide a tool for testing and improving roles in a systematic but flexible manner. Our concept suggests an all-participatory approach, combining the ideas of external 'role' design [18] and 'role' crafting [29] from the role inhabitants themselves. Therefore, the concept, along with the design goals and principles, provides a comprehensible design routine and distributes the wealth of information into managerial steps, enabling a focus on the incremental flow of improvement and optimization.

\section{Concluding Remarks and Further Research}

Our research contributes to theory and practice by developing three design goals, six design principles, and a concept that can serve as an underlying guideline for organizations to build adequate and flexible roles in agile transformations. The study explicitly links the understanding of agility with the concept of roles and deepens the understanding of the underlying strategies of agile role development and refinement.

The study is not without limitations. First, the data collection in software and IT dominated organizations limit the generalizability and application of the results in nonIT industries and departments. Second, the concept is imprecise in the explicit illustration of strategic imperatives, as the research has a dominant focus on the operational level. Furthermore, the DSR method is not non-judgmental, as the design of the artifact can be subjected by the desire to yield a specific benefit and reach a particular objective [40]. Finally, the qualitative analysis of the interviews is also naturally affected by the researcher's biases and assumptions [45], despite the strict adherence to the grounded theory methodology.

To better understand the implications of this research and the results, further research should address the applicability of the method and the design goals and principles in cross-sector investigations. Quantitative studies could measure the importance and prioritization in practical applications and determining the causes and effects between the design goals and principles and the corresponding role definitions and structures. Additionally, qualitative case studies could provide a broader picture of agile roles concerning industry and context factors. As the study could not rely on a grounded definition or conceptualization of agile roles; we recommend further field spanning and integration of the whole research field. 


\section{$7 \quad$ Appendix}

Table 1. Coding Example

\begin{tabular}{|c|c|c|c|}
\hline $\begin{array}{l}\text { Selective } \\
\text { Coding }\end{array}$ & $\begin{array}{l}\text { Axial } \\
\text { Coding }\end{array}$ & Open Coding & Exemplary data \\
\hline \multirow{5}{*}{$\begin{array}{l}\text { Role } \\
\text { development } \\
\text { challenges }\end{array}$} & & $\begin{array}{l}\text { Change } \\
\text { resistance \& } \\
\text { Uncertainty }\end{array}$ & $\begin{array}{l}\text { "People say [...] this is not my job description from my } \\
\text { employment contract that's why I won't do it." } \\
\text { (TPAM08, translated) }\end{array}$ \\
\hline & $\begin{array}{l}\text { People } \\
\text { challenges }\end{array}$ & $\begin{array}{l}\text { People's } \\
\text { abilities \& } \\
\text { capabilities }\end{array}$ & $\begin{array}{l}\text { "Minimal training in agile [...] Jand all of a sudden you } \\
\text { need to act differently and the people in your team need } \\
\text { to act differently and become self-steering and you need } \\
\text { to become a servant leader while you are actually a } \\
\text { command-and-control type that's a double difficulty." } \\
\text { (TPOE03) }\end{array}$ \\
\hline & \multirow{2}{*}{$\begin{array}{l}\text { Operational } \\
\text { challenges }\end{array}$} & $\begin{array}{l}\text { Staffing \& } \\
\text { resources }\end{array}$ & $\begin{array}{l}\text { "It can be difficult depending on what resources (people) } \\
\text { are available." (TPAD04) }\end{array}$ \\
\hline & & Finances & $\begin{array}{l}\text { "The number of team members is strictly shaped by the } \\
\text { budget." (TPPM11) }\end{array}$ \\
\hline & $\begin{array}{l}\text { Man. \& } \\
\text { Org. } \\
\text { challenges }\end{array}$ & $\begin{array}{l}\text { Decision- } \\
\text { making }\end{array}$ & $\begin{array}{l}\text { "Here again one would have to look at how certain } \\
\text { decisions have to be made (e.g.) with the management." } \\
\text { (TPAM08, translated) }\end{array}$ \\
\hline
\end{tabular}

\section{References}

1. Beck, K.: Extreme programming explained. Embrace change. Addison-Wesley, Boston (1999)

2. Schwaber, K., Beedle, M.: Agile software development with Scrum. Prentice Hall, Upper Saddle River, NJ (2002)

3. Stapleton, J.: DSDM: Dynamic Systems Development Method. Addision-Wesley, Harlow (1997)

4. Manifesto for Agile Software Development, https://agilemanifesto.org/ (Accessed: 20.11.2020)

5. Laanti, M.: Agile transformation model for large software development organizations. In: Tonelli, R. (ed.) Proceedings of the XP2017 Scientific Workshops on - XP '17, pp. 1-5. ACM Press, New York, New York, USA (2017)

6. Denning, S.: The ten stages of the Agile transformation journey. Strategy \& Leadership 47, 3-10 (2018)

7. Gandomani, T.J., Nafchi, M.Z.: The Essential Prerequisites of Agile Transition and Adoption: a Grounded Theory Approach. Journal of Internet Computing and Services 17, 173-184 (2016)

8. Leffingwell, D.: SAFe reference guide. Scaled Agile Framework for lean software and systems engineering: SAFe 4.5. Scaled Agile Inc; Pearson AddisonWesley, Boulder, Colorado, USA (2018)

9. Larman, C., Vodde, B.: Large-scale scrum. More with less. Addison-Wesley, Boston (2017)

10. Ambler, S.W., Lines, M.: Disciplined Agile Delivery. A practitioner's guide to agile software delivery in the enterprise. IBM Press, New Jersey (2012) 
11. Conboy, K.: Agility from First Principles. Reconstructing the Concept of Agility in Information Systems Development. Information Systems Research 20, 329354 (2009)

12. Jovanović, M., Mas, A., Mesquida, A., Lalić, B.: Transition of organizational roles in Agile transformation process. A grounded theory approach. Journal of Systems and Software 133, 174-194 (2017)

13. Moe, N.B., Stray, V., Hoda, R.: Trends and Updated Research Agenda for Autonomous Agile Teams. A Summary of the Second International Workshop at XP2019. In: Rashina Hoda, Wil van der Aalst, John Mylopoulos, Michael Rosemann, Michael J. Shaw, Clemens Szyperski (eds.) Agile Processes in Software Engineering and Extreme Programming - Workshops. XP 2019 Workshops, pp. 13-19. Montreal, QC, Canada (2019)

14. Schwaber, K., Sutherland, J.: The Scrum Guide. The Definitive Guide to Scrum: The Rules of the Game, https://www.scrumguides.org/scrum-guide.html\#events (Accessed: 04.10.2020)

15. Yilmaz, M., O`Connor, R., Clarke, P.: Software Development Roles. A MultiProject Empirical Investigation. ACM SIGSOFT Software Engineering 40, 1-5 (2015)

16. Burlton, R.T.: Business process management. Profiting from process. Sams, Indianapolis (2001)

17. Downey, J.: An artifact-centric method for creating software job descriptions. In: Lending, D., Vician, C., Riemenschneider, C., Armstrong, D.J. (eds.) Proceedings of the 2008 ACM SIGMIS CPR conference on Computer personnel doctoral consortium and research - SIGMIS-CPR '08, pp. 12-21. ACM Press, New York, New York, USA (2008)

18. Schreyögg, G., Geiger, D.: Organisation. Grundlagen moderner Organisationsgestaltung: mit Fallstudien. Springer Gabler, Wiesbaden (2016)

19. Cohen, L.E., Burton, M.D., Lounsbury, M.: Introduction: Bringing Jobs back in. Toward a New Multi-Level Approach to the Study of Work and Organizations. In: Cohen, L.E., Burton, M.D., Lounsbury, M. (eds.) The structuring of work in organizations, pp. 1-22. Emerald Group Publishing Limited, Bingley, UK (2016)

20. Turner, R.H.: Role Theory. In: Turner, J.H. (ed.) Handbook of Sociological Theory, pp. 233-254. Springer, Riverside (2006)

21. Hevner, A.R., March, S.T., Park, J., Ram, S.: Design Science in Information Systems Research. MIS Quarterly 28, 75-105 (2004)

22. Dybå, T., Dingsøyr, T.: Empirical studies of agile software development. A systematic review. Information and Software Technology 50, 833-859 (2008)

23. Dubinsky, Y., Hazzan, O.: Roles in Agile Software Development Teams. In: Eckstein, J., Baumeister, H. (eds.) Extreme Programming and Agile Processes in Software Engineering. 5th International Conference, XP 2004, GarmischPartenkirchen, Germany, June 6-10, 2004. Proceedings, pp. 157-165. Springer, Berlin, Heidelberg (2004)

24. Uludag, O., Kleehaus, M., Xu, X., Matthes, F.: Investigating the Role of Architects in Scaling Agile Frameworks. In: 2017 IEEE 21st International 
Enterprise Distributed Object Computing Conference (EDOC), pp. 123-132. $\operatorname{IEEE}(2017)$

25. Mead, G.H.: Mind, Self, and Society. From a standpoint of a social behaviorist. Univ. of Chicago Press, Chicago (1934)

26. Cohen, L.E.: Assembling Jobs: A Model of How Tasks Are Bundled Into and Across Jobs. Organization Science 24, 432-454 (2013)

27. Lawrence, P.R., Lorsch, J.W.: Organization and Environment. Managing Differentiation and Integration. Harvard University Press, Cambridge (1967)

28. Cohen, S.G., Mankin, D.: The Changing Nature of Work: Managing the Impact of Information Technology. In: Mohrman, S.A., Galbraith, J.R., Lawler, E.E. (eds.) Tomorrow's organization. Crafting winning capabilities in a dynamic world, pp. 154-178. Jossey-Bass Publ, San Francisco, Calif. (1998)

29. Wrzesniewski, A., Dutton, J.E.: Crafting a Job: Revisioning Employees as Active Crafters of Their Work. The Academy of Management Review 26, 179-201 (2001)

30. Gully, S.M., Incalcaterra, K.A., Joshi, A., Beauien, J.M.: A meta-analysis of team-efficacy, potency, and performance: interdependence and level of analysis as moderators of observed relationships. The Journal of applied psychology 87, 819-832 (2002)

31. Kozlowski, S.J.W., Bell, B.S.: Work Groups and Teams in Organizations. In: Weiner, I.B. (ed.) Handbook of psychology, 42, pp. 333-375. Wiley, Hoboken, New Jersey (2013)

32. Kalenda, M., Hyna, P., Rossi, B.: Scaling agile in large organizations: Practices, challenges, and success factors. Journal of Software: Evolution and Process 30, 1 24 (2018)

33. Paasivaara, M.: Adopting SAFe to Scale Agile in a Globally Distributed Organization. 2017 IEEE 12th International Conference on Global Software Engineering (ICGSE), 36-40 (2017)

34. Paasivaara, M., Behm, B., Lassenius, C., Hallikainen, M.: Large-scale agile transformation at Ericsson. A case study. Empirical Software Engineering 23, 2550-2596 (2018)

35. Misra, S.C., Kumar, V., Kumar, U.: Identifying some important success factors in adopting agile software development practices. Journal of Systems and Software 82, 1869-1890 (2009)

36. Fuchs, C., Hess, T.: Becoming Agile in the Digital Transformation: The Process of a Large-Scale Agile Transformation. Thirty Ninth International Conference on Information Systems San Francisco, 1-17 (2018)

37. Gerster, D., Dremel, C., Kelker, P.: "Agile Meets Non-Agile": Implications of Adopting Agile Practices at Enterprises. Twenty-fourth Americas Conference on Information Systems New Orleans, 1-10 (2018)

38. Kiely, G., Kiely, J., Nolan, C.: Scaling Agile Methods to Process Improvement Projects: A Global Virtual Team Case Study. Twenty-third Americas Conference on Information Systems Boston, 1-9 (2017)

39. Meth, H., Mueller, B., Maedche, A.: Designing a Requirement Mining System. Journal of the Association for Information Systems 66, 799-837 (2015) 
40. Peffers, K., Tuunanen, T., Rothenberger, M.A., Chatterjee, S.: A Design Science Research Methodology for Information Systems Research. Journal of Management Information Systems 24, 45-77 (2007)

41. Gregor, S., Hevner, A.R.: Positioning and Presenting Design Science Research for Maximum Impact. MIS Quarterly 37, 337-355 (2013)

42. Kim, S., Lee, H., Kwon, Y., Yu, M., Jo, H.: Our Journey to Becoming Agile. Experiences with Agile Transformation in Samsung Electronics. Asia-Pacific Software Engineering Conference 23, 377-380 (2016)

43. Paasivaara, M., Lassenius, C.: Scaling Scrum in a Large Globally Distributed Organization: A Case Study. IEEE 11th International Conference on Global Software Engineering, 74-83 (2016)

44. Gat, I.: How BMC is Scaling Agile Development. Proceedings of AGILE 2006 Conference (2006)

45. Corbin, J.M., Strauss, A.L.: Basics of qualitative research. Techniques and procedures for developing grounded theory. SAGE, Los Angeles, London, New Delhi, Singapore, Washington DC, Boston (2015)

46. Gregor, S., Jones, D.: The Anatomy of a Design Theory. Journal of the Association for Information Systems 8, 312-335 (2007)

47. Gunasekaran, A.: Agile manufacturing. A framework for research and development. International Journal of Production Economics 62, 87-105 (1999)

48. Womack, J.P., Jones, D.T.: Lean Thinking-Banish Waste and Create Wealth in your Corporation (1996)

49. Sambamurthy, V., Bharadwaj, A., Grover, V.: Shaping Agility through Digital Options: Reconceptualizing the Role of Information Technology in Contemporary Firms. MIS Quarterly 2, 237-263 (2003)

50. Overby, E., Bharadwaj, A., Sambamurthy, V.: Enterprise agility and the enabling role of information technology. European Journal of Information Systems 15, 120-131 (2006)

51. Hur, W., Shin, Y., Rhee, S., Kim, H.: Organizational virtuousness perceptions and task crafting. Career Development International 22, 436-459 (2017)

52. Feldman, M.S., Pentland, B.T.: Reconceptualizing Organizational Routines as a Source of Flexibility and Change. Administrative Science Quarterly 48, 94-118 (2003)

53. Santos, W.B., Cunha, J. A. O. G., Moura, H., Margaria, T.: Towards a Theory of Simplicity in Agile Software Development: A Qualitative Study. In: Felderer, M., Holmström Olsson, H., Skavhaug, A. (eds.) 43rd Euromicro Conference on Software Engineering and Advanced Applications. SEAA 2017: proceedings: 30 August-1 September 2017, Vienna, Austria, pp. 40-43. IEEE, Piscataway, NJ (2017)

54. Gorschek, T., Wohlin, C.: Requirements Abstraction Model. Requirements Engineering 11, 79-101 (2005)

55. Dikert, K., Paasivaara, M., Lassenius, C.: Challenges and success factors for large-scale agile transformations. A systematic literature review. Journal of Systems and Software 119, 87-108 (2016) 